ÉRICO XAVIER DESTERRO E SILVA

\title{
O CONTROLE DA EFICIÊNCIA ADMINISTRATIVA PELO TRIBUNAL DE CONTAS
}

\author{
Dissertação de Mestrado \\ Orientador: Professor Doutor Edmir Netto de Araújo
}

UNIVERSIDADE DE SÃO PAULO

FACULDADE DE DIREITO

São Paulo-SP

2020 


\title{
ÉRICO XAVIER DESTERRO E SILVA
}

\section{O CONTROLE DA EFICIÊNCIA ADMINISTRATIVA PELO TRIBUNAL DE CONTAS}

\begin{abstract}
Dissertação apresentada à Banca Examinadora do Programa de Pós-Graduação em Direito, da Faculdade de Direito da Universidade de São Paulo, como exigência parcial para obtenção do título de Mestre em Direito, na área de concentração Direito do Estado, sob a orientação do Professor Doutor Edmir Netto de Araújo.
\end{abstract}

UNIVERSIDADE DE SÃO PAULO

FACULDADE DE DIREITO

São Paulo-SP

2020 
Catalogação da Publicação

Serviço de Biblioteca e Documentação

Faculdade de Direito da Universidade de São Paulo

Silva, Érico Xavier Desterro e

- controle da eficiência administrativa pelo

tribunal de contas : Érico Xavier Desterro e Silva ; orientador Edmir Netto de Araújo -- São Paulo, 2020.

168

Dissertação (Mestrado - Programa de Pós-Graduação em Direito do Estado) - Faculdade de Direito, Universidade de São Paulo, 2020.

1. Eficiência administrativa. 2. Princípio da eficiência. 3. Controle Externo. 4. Controle da eficiência administrativa. 5. Tribunal de Contas. I. Araújo, Edmir Netto de, orient. II. Título. 


\section{FOLHA DE APROVAÇÃO}

Érico Xavier Desterro e Silva

O controle da eficiência administrativa pelo Tribunal de Contas

Dissertação apresentada à Banca Examinadora do Programa de Pós-Graduação em Direito, da Faculdade de Direito da Universidade de São Paulo, como exigência parcial para obtenção do título de Mestre em Direito, na área de concentração Direito do Estado, sob a orientação do Professor Doutor Edmir Netto de Araújo.

Aprovado em:

Banca Examinadora

Professor Dr. Edmir Netto de Araújo (Orientador) 


\section{AGRADECIMENTOS}

Durante vários meses, venho silenciosamente agradecendo a todos os que me têm ajudado neste trabalho. É a oportunidade de externar tudo isso.

À Faculdade de Direito, da Universidade de São Paulo, aos seus Professores e corpo de funcionários, pelo acolhimento e atenção dispensados.

Aos funcionários do Tribunal de Contas do Estado do Amazonas, que trabalham próximos a mim, pelo apoio dado, possibilitando que eu não me afastasse do exercício de minhas atribuições, durante a realização deste Mestrado.

Ao João Paulo Jacob, meu amigo, incentivador desde o início e constante socorro nos momentos mais difíceis.

Os meus sinceros agradecimentos à Professora Ana Maria Pedreira, pelos valiosos conselhos e observações.

Ao Professor Edmir Netto de Araújo, orientador deste trabalho; sou-lhe imensamente grato por me ter aceitado como aluno, mas, sobretudo, como amigo, e por me ter proporcionado muito mais do que lições de Direito, mas um aprendizado para a vida, em conversas inesquecíveis.

À Milena e à Clarissa, razão de tudo.

A Deus, por ter posto na minha vida todas essas pessoas maravilhosas. 
SILVA, Érico Xavier Desterro e Silva. O controle da eficiência administrativa pelo Tribunal de Contas. 2020. 168f. Dissertação (Mestrado). Faculdade de Direito da Universidade de São Paulo, São Paulo, 2020.

\section{RESUMO}

Esta dissertação tem por objetivo demonstrar que a inserção do Princípio da Eficiência no art. 37, da Constituição do Brasil, produziu, como efeito imediato, além da exigência objetiva do dever de eficiência de toda a atividade administrativa, a possibilidade e necessidade de seu efetivo controle. No desenvolvimento da pesquisa foi demonstrado que, muito embora a eficiência deva ser objeto do autocontrole administrativo e que também se insere nas possibilidades de exame dos atos administrativos por parte do Poder Judiciário, é o Tribunal de Contas o órgão constitucionalmente legitimado, de forma precípua, à realização de seu controle sistemático. A pesquisa foi realizada através do método bibliográfico, dedutivo e analítico, por meio de análises doutrinárias e jurisprudenciais. São abordados os aspectos as características principais da atividade controladora, no Brasil, destacando-se os órgãos que fazem parte do sistema de controle, as suas competências e a forma de exercê-las; depois o texto demonstra o papel que foi destinado, pela Constituição de 1988, ao Tribunal de Contas, ressaltando as competências que lhe foram previstas e, igualmente, as perspectivas possíveis de controle que deve exercer. Analisa-se, ainda, a eficiência administrativa como um princípio constitucional, buscando demonstrar o seu conteúdo jurídico, além das circunstâncias, razões e consequências de sua inserção expressa no Texto Constitucional. Por fim, cuida-se do fundamento de seu controle pelo Tribunal de Contas, a quem a Constituição determinou que realizasse a fiscalização contábil, financeira, orçamentária, patrimonial e operacional, quanto à legalidade, legitimidade e economicidade, dentre outros aspectos; são examinadas também as amplas possibilidades de controle que podem/devem ser exercidas por esse órgão, tratando-se das formas e metodologias aplicáveis. Como resultado, concluiu-se que o Tribunal de Contas não somente é o órgão com titularidade constitucional para exercer o controle da eficiência administrativa, mas também tem o perfil técnico adequado a esta análise, devendo proceder cada vez mais ao controle da administração pública, quanto aos seus resultados.

Palavras-chave: Eficiência administrativa. Princípio da eficiência. Atividade controladora. Controle Externo. Controle da eficiência administrativa. Tribunal de Contas. 
SILVA, Érico Xavier Desterro e Silva. Control of administrative efficiency by the Court of Audit. 2020. 168f. Master's Dissertation - Course of Law, University of São Paulo, 2020.

\begin{abstract}
This dissertation aims to demonstrate that the insertion of the Efficiency Principle in art. 37, of the Constitution of Brazil, produced, as an immediate effect, in addition to the objective requirement of the duty of efficiency of all administrative activity, the possibility and necessity of its effective control. In the development of the research, it was demonstrated that, although efficiency must be the object of administrative self-control and that it is also part of the possibilities of examining administrative acts by the Judicial Branch, the Court of Audit is the constitutionally legitimate institution, in a primary way, carrying out its systematic control. The research was carried out through the bibliographic, deductive and analytical methods, through doctrinal and jurisprudential analyses. The main aspects and characteristics of the controlling activity in Brazil, are addressed highlighting the organs that are part of the control system, their competences and the way to exercise them; then, the text demonstrates the role that was assigned, by the 1988 Constitution, to the Court of Audit, emphasizing the competences that were provided for it and, equally, the possible prospects of control that it should exercise. Administrative efficiency is also analysed as a constitutional principle, seeking to demonstrate its legal content, in addition to the circumstances, reasons and consequences of its inclusion in the Constitutional Text. Finally, it addresses the basis for its control by the Court of Audit, whom the Constitution determined to carry out accounting, financial, budgetary, patrimonial and operational inspection, regarding legality, legitimacy and economy, among other aspects; the wide possibilities of control that can / should be exercised by this institution are also examined, considering the applicable forms and methodologies. As a result, it was concluded that the Court of Audit is not only the institution with constitutional authority to exercise control over administrative efficiency, but also has the appropriate technical profile for this analysis, and should increasingly control the public administration regarding its results.
\end{abstract}

Key-words: Administrative Efficiency. Principles of Efficiency. Controling Activity. External Control. Administrative Efficiency. 


\section{LISTA DE ABREVIATURAS}

CF/1988 - Constituição da República Federativa do Brasil de 1988

CNJ - Conselho Nacional de Justiça

CPA - Código de Processo Administrativo (Portugal)

DJe - Diário de Justiça eletrônico

GAO - Departamento Geral de Auditoria (EUA)

INTOSAI - International Organisation of Superior Audit Institutions

ISSAI - Normas Internacionais das Entidades Fiscalizadoras Superiores

LINDB - Lei de Introdução à Normas do Direito Brasileiro (Decreto-Lei 4657, de 4 de setembro de 1942)

LRF - Lei de Responsabilidade Fiscal (Lei Complementar n. 101, de 0 de maio de 2000)

NAO - Departamento Nacional de Auditoria (Reino Unido)

OECD - Organization for Economic Cooperation and Development

RRV - Riksrevisionsverkket (Suécia)

STF - Supremo Tribunal Federal

STJ - Superior Tribunal de Justiça

TCE-AM - Tribunal de Contas do Estado do Amazonas

TCE-RS - Tribunal de Contas do Estado do Rio Grande do Sul

TCE-SP - Tribunal de Contas do Estado de São Paulo

TCU - Tribunal de Contas da União

TJUE - Tribunal de Justiça da União Europeia

VTV - Valtiontalouden tarkastusvirasto (Finlândia) 


\section{SUMÁRIO}

INTRODUÇÃO 9

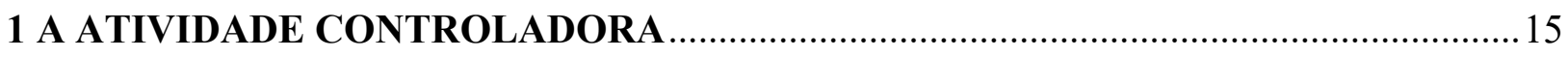

1.1 O Princípio da Separação dos Poderes e o controle ..........................................................15

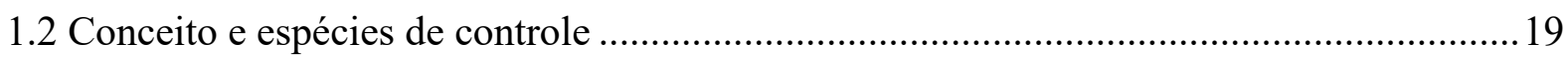

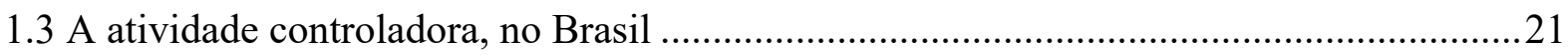

1.4 A Lei de Introdução às Normas do Direito Brasileiro e a atividade controladora ..............25

2 O CONTROLE EXERCIDO PELOS TRIBUNAIS DE CONTAS ………………….........33

2.1 O controle externo da Administração Pública ………………………………………........33

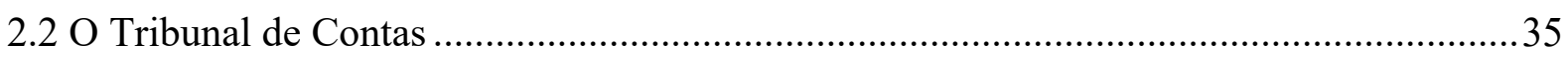

2.2.1 Posição constitucional do Tribunal de Contas ................................................................35

2.2.2 As funções e competências do Tribunal de Contas..........................................................39

2.2.3 Aspectos do controle realizado pelo Tribunal de Contas.............................................48

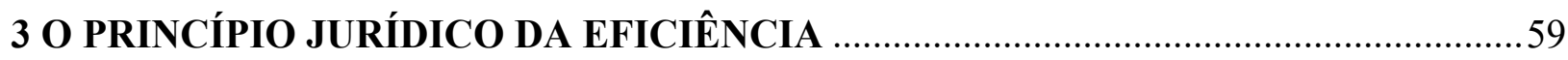

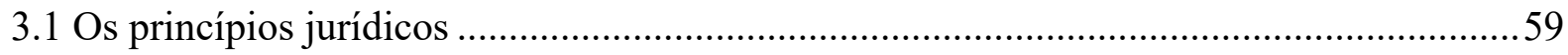

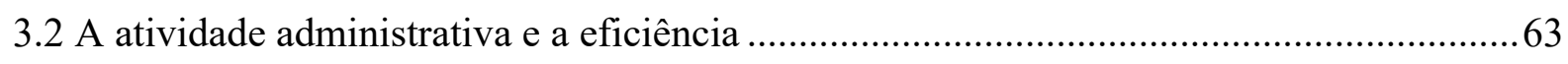

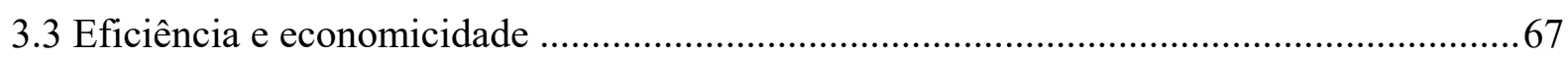

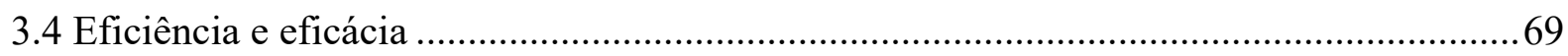

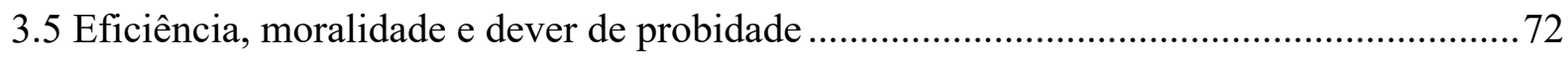

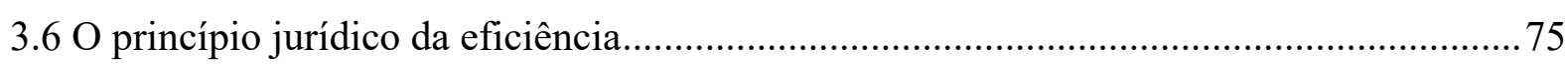

3.6.1 O princípio da eficiência e o princípio da boa administração ........................................80

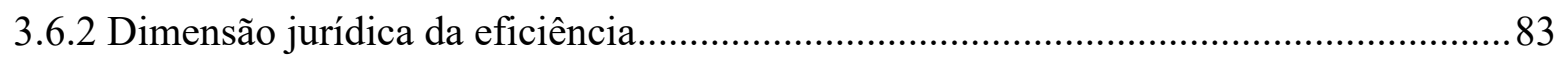

3.6.3 O princípio da eficiência e os agentes públicos........................................................91

3.6.4 O princípio da eficiência e o serviço público ................................................................97

3.6.5 O princípio da eficiência e o processo administrativo ................................................ 100

3.7 Novos mecanismos de execução das atividades de interesse público ................................ 105

4 O CONTROLE DA EFICIÊNCIA PELOS TRIBUNAIS DE CONTAS ……………........ 109

4.1 Premissas para uma análise do controle da eficiência pelos tribunais de contas ............. 109

4.2 O Tribunal de Contas como órgão constitucionalmente legitimado para o controle

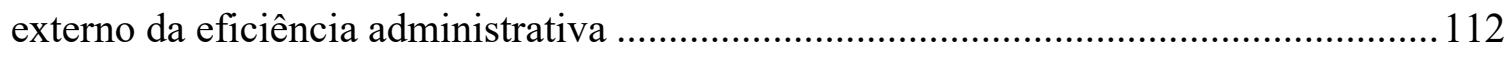

4.3 Mecanismos e oportunidades de controle da eficiência administrativa pelos tribunais de contas. 
4.3.1 Auditoria operacional e o controle de resultados 122

4.3.1.1 O controle de resultados pelos Tribunais de Contas brasileiros.......................... 125

4.3.1.2 Auditoria operacional e controle de resultados em outros países 129

4.3.2 A auditoria de regularidade e o controle da eficiência 134

4.3.3 Controle sobre as políticas públicas, planejamento e eficiência orçamentária. 139

4.3.4 Controle da eficiência da prestação de serviços públicos. 142

4.3.5 Controle da eficiência orçamentária 144

4.4 Parâmetros para o controle 147

CONCLUSÃO 149

REFERÊNCIAS 155 


\section{INTRODUÇÃO}

Ninguém desconhece a importância da Administração Pública na consecução dos interesses públicos ou coletivos. Agindo sob um regime jurídico diferente do comum, que possui, por lógico, princípios que lhe são próprios e interconexos, existe para a satisfação do somatório de interesses dos indivíduos, considerados como partes (participantes) da sociedade. A existência de um sistema jurídico-administrativo só é possível num Estado de Direito; no início, personificando o próprio Estado e lhe atribuindo, na relação jurídica, evidente supremacia em relação ao administrado, mas, também, submetendo-o à regra da legalidade, ainda que o controle jurisdicional de sua atividade fosse limitado por uma leitura rígida da separação dos poderes. Depois, em um segundo momento, registrase um considerável crescimento das atividades estatais e, de forma igual, uma crescente preocupação com a tutela dos direitos dos administrados, acompanhado de uma reformulação da ideia de legalidade (para entendê-la como juridicidade), de uma mitigação da imperatividade dos atos administrativos e de maiores possibilidades de controle jurisdicional da discricionariedade.

A fase atual do direito administrativo, cujo início pode ser identificado a partir do fim do século passado, caracteriza-se pela necessidade de a Administração Pública dar respostas à generalizada insatisfação com a qualidade dos seus serviços em contraposição aos seus elevados custos; essa exigência decorre do alargamento dos escopos e de mecanismos de controle externo da atividade administrativa, nas suas variadas modalidades, com destaque para o incremento da tutela judicial dessa atividade e pela efetivação do controle social com as mudanças tecnológicas experimentadas nos últimos tempos, causando uma verdadeira revolução informacional.

$\mathrm{Na}$ busca de respostas e soluções para essa insatisfação com a atividade estatal, foram propostos novos parâmetros para a gestão pública, com uma crescente tendência a buscar, na atividade privada, os elementos necessários para a sua transformação. $\mathrm{O}$ próprio discurso é remodelado para atender a essa nova perspectiva de ação do Estado: o cidadão visto como um "cliente", "down-sizing" do setor público, privatização, "contracting out" etc. O sistema jurídico-administrativo, então, como reflexo da influência de modos gestionários das empresas privadas que se pretende sejam aplicados ao setor público, igualmente passa a receber institutos jurídicos do Direito Privado ou tem 
remodelada a dimensão ou significação dos seus próprios institutos, naquilo que se consagrou chamar de "fuga para o Direito Privado". São claros exemplos disso, a introdução de novas modalidades contratuais, a participação crescente de particulares na execução de atividades ou funções públicas e na forma como a própria Administração passa a se estruturar para a execução direta dos serviços por ela prestados.

Nesse contexto é inevitável suscitar o problema da eficácia ou efetividade da ação estatal, que, no Brasil, sem dúvida, ao lado da corrupção, é a questão principal envolvida em todas as reformulações que dizem respeito à Administração Pública. A partir dos anos 1990, após uma análise dos problemas estruturais da Administração Pública brasileira, uma reforma foi introduzida no ordenamento constitucional, com a previsão de novos conceitos, institutos, mecanismos de caráter eminentemente gerencial. Dentre as modificações, foi feita a inclusão da eficiência entre os expressos princípios constitucionais aplicados à atividade administrativa.

Como pretendemos demonstrar, a formulação constitucional de um princípio da eficiência não é algo simplesmente retórico, como parte da doutrina alegou que fosse. A sua introdução na Constituição Federal de 1988 como um princípio expresso da atividade da Administração, certamente, não produziu o efeito imediato de torná-la eficiente, nem se pode dizer que, passadas duas décadas, já tenhamos uma Administração Pública que atenda aos anseios da sociedade, no que diz respeito a resultados eficazes de sua ação. Isso, contudo, não invalida o raciocínio que pretendemos desenvolver sobre a importância do princípio da eficiência no sistema jurídico e, mais ainda, a relevância de sua formulação expressa no art. 37 da Constituição Federal vigente, ao lado da legalidade, impessoalidade, moralidade e publicidade, tendo, como uma de suas consequências práticas e imediatas, a possibilidade de ser controlada a atividade administrativa sob o ponto de vista da eficiência em novos moldes.

O propósito nuclear desta dissertação é demonstrar que:

i) sendo a eficiência um princípio positivado no Direito brasileiro tal como a legalidade, moralidade, impessoalidade e publicidade, deverá ser observada sempre pela Administração Pública na adoção de seus atos e decisões;

ii) a exemplo do que ocorre com os demais princípios, deve ser ele controlável pelos órgãos e meios constitucionalmente legitimados, nos limites e alcances da atuação de cada um deles; 
(iii) os tribunais de contas, como órgãos constitucionais, cuja função precípua é a atividade controladora, estão legitimados e são os principais responsáveis pelo controle externo da eficiência administrativa; e

(iv) o controle exercido pelos tribunais de contas, quanto à eficiência da atividade da Administração, assume variados aspectos que não se limitam à emissão de relatórios endereçados ao Poder Legislativo ou à sociedade, mas que podem levar à reprovação das contas do gestor público, com a aplicação de sanções de natureza administrativa.

Imperioso, então, é que, inicialmente, tratemos da atividade de controle. Algumas observações sobre o sistema de controle da Administração Pública, no Brasil, são necessárias, com ênfase no controle externo. Refletiremos sobre a autonomia da atividade controladora, dedutível das disposições constitucionais e hoje claramente enunciada pelas modificações mais recentes da Lei de Introdução às Normas do Direito Brasileiro.

O segundo capítulo será reservado ao controle exercido pelos tribunais de contas, como não poderia deixar de ser. Embora bastante discutida na doutrina, a questão referente à posição constitucional desses órgãos de controle, no atual ordenamento jurídico, ainda é objeto de controvérsias. Malgrado a unanimidade dos autores que tratam do assunto ressaltar que os tribunais de contas possuem grande importância no sistema de controle da administração e, igualmente, reconhecerem que a CF/1988 aumentou consideravelmente as suas competências, há, ainda, enorme resistência em relação à amplitude dessas atribuições e às suas reais possibilidades de serem órgãos de controle efetivo.

A natureza e a perspectiva do controle realizado pelos tribunais de contas são, com frequência, objeto de controvérsias, mas é inegável avanço que na atualidade (embora não seja exatamente uma novidade) já se perceba a maior relevância de um controle de resultados, das metas e dos programas de trabalho, em relação a uma fiscalização meramente formal, contábil e financeira. É auspicioso que se reconheça, já agora, o papel dos tribunais de contas no controle de políticas públicas.

Igualmente será feita uma análise sobre o princípio da eficiência no Direito brasileiro. Ainda que muito sucintamente, uma explicação sobre o papel desempenhado pelos princípios, nos ordenamentos jurídicos, é necessária por diversas razões, mas, sobretudo, para afirmar, mais tarde, a completa possibilidade de sindicância da sua efetividade nas atividades da Administração Pública. Além disso, será feito o exame das circunstâncias em que esse princípio foi posto expressamente entre os princípios da 
Administração Pública, muito embora isso não seja determinante do real significado de sua formulação no texto constitucional, mormente no contexto atual. A sempre mencionada vinculação entre a introdução do princípio da eficiência no caput do art. 37 , da Constituição Federal atual, e o movimento dos anos 1980 da década passada de reformar o Estado brasileiro (ou mais precisamente, a administração pública brasileira) será abordada. Demonstraremos, entretanto, que independentemente das razões pelas quais o Princípio da Eficiência foi introduzido expressamente no Texto Constitucional, a sua importância atual está em ser uma exigência objetiva da atividade administrativa e uma referência à necessidade de serem adotados mecanismos modernos de gestão e governança públicas.

Decorre do direito fundamental a uma boa administração, a imposição ao Poder Público de uma atuação adequada aos valores constitucionalmente protegidos, dentre eles, a eficiência na execução da atividade administrativa. Na busca de uma dimensão jurídica da eficiência, serão analisados os elementos que proporcionam uma ligação lógica com outros conceitos e valores do sistema jurídico, como a moralidade, a economicidade e a eficácia, estabelecendo-se as relações existentes entre eles e as suas respectivas dimensões conceituais. Para tanto, a pesquisa alcançará a experiência de alguns outros ordenamentos jurídicos. Também serão analisados, no Direito Positivo brasileiro, as manifestas exigências de eficiência, quer como um aspecto da atuação dos agentes públicos, quer como uma qualidade intrínseca da prestação dos serviços públicos; os mecanismos e instrumentos jurídicos introduzidos no ordenamento nacional a partir do final do século passado ou o aperfeiçoamento daqueles que já se encontravam postos serão igualmente examinados.

$\mathrm{Na}$ última parte deste texto investigativo, após as necessárias e indispensáveis considerações antes mencionadas, será feita a análise sobre a atuação dos Tribunais de Contas no que respeita ao controle da eficiência. Partindo dos pressupostos alinhados nos capítulos anteriores, demonstraremos que esses órgãos, exercentes das atividades controladoras, são verdadeiramente legitimados ao controle da Administração Pública não só sob os aspectos de conformidade legal ou numérico-formal, mas, igualmente, quanto à atuação adequada sob o ponto de vista de resultados.

Essa abordagem final englobará uma análise da atuação possível dos órgãos de controle, tratando especificamente dos seguintes aspectos: mecanismos e instrumentos de 
fiscalização e auditoria; oportunidade, objeto e alcance do controle; metodologia e consequências da atividade controladora sob o aspecto da eficiência.

Acerca da metodologia que envolveu a investigação e o desenvolvimento da pesquisa para sua elaboração, destacamos que o estudo está concentrado no levantamento bibliográfico doutrinário e jurisprudencial acerca do controle da atividade estatal e o princípio da eficiência. Como se sabe, na área do Direito, adota-se uma metodologia fundamentalmente dogmática, com enfoques analíticos e normativos. O método analítico foi utilizado sobre os aspectos temáticos, buscando-se, na doutrina jurídica brasileira, os fundamentos teóricos do controle, a repercussão dos institutos a ele ligados e as suas peculiaridades.

De forma concomitante recorre-se ao exame de trabalhos doutrinários, a análise comparativa de diplomas normativos (Constituição Federal vigente, leis, atos normativos infralegais, etc.), cujo levantamento e catalogação dos principais textos relacionados ao tema foram feitos invariavelmente por meio de leitura qualificada e com o objetivo de identificar o tratamento normativo conferido aos tribunais de contas no Direito brasileiro.

Por derradeiro, levando-se em conta que a ciência jurídica busca incessantemente uma relação entre o particular e o universal e um equilíbrio entre teoria e prática ${ }^{1}$, a abordagem empírica foi suplementar aos destaques doutrinários e normativos e valeu-se de casos da jurisprudência judicial e dos próprios tribunais de contas, fundamentalmente do Tribunal de Contas da União.

Para o desenvolvimento apropriado da pesquisa, foram adotadas algumas hipóteses ou questionamentos principais, a fim de demarcar ainda mais o campo de estudo, orientar a investigação e possibilitar, finalmente, uma compreensão sistemática do assunto em comento.

Os questionamentos que devem guiar a investigação são os seguintes:

1.)Quais as efetivas consequências da previsão explícita do princípio da eficiência administrativa na Constituição Brasileira atual?

2.) A eficiência administrativa é um valor jurídico controlável objetivamente pelos órgãos de controle da Administração Pública?

\footnotetext{
${ }^{1}$ FLORES, Alfredo de J. O estudo de casos na perspectiva da metodologia jurídico-filosófica. Revista Eletrônica do Curso de Direito da UFSM, v. 4, n. 3, p. 9, 2009. Disponível em: http://dx.doi.org/10.5902/198136947036. Acesso em: 12 jun. 2016.
} 
3.)Qual a extensão do controle que pode ser realizado em relação à eficiência administrativa? Os atos e as decisões administrativas podem ser objeto de controle sob o ponto de vista da eficiência dos seus resultados?

4.) Quais as possibilidades, formas, extensão e consequências do controle exercido pelo Tribunal de Contas quanto à eficiência da Administração Pública? De que forma o Tribunal de contas pode melhorar a qualidade de sua atuação, visando fiscalizar a eficiência dos atos da Administração?

Ao final, à guisa de conclusão, apresentamos as respostas a estes questionamentos. 


\section{CONCLUSÃO}

1. A Administração Pública precisa dar respostas adequadas à insatisfação com a qualidade dos seus serviços prestados e com a execução das suas atividades, de uma forma geral, mormente se levados em consideração os seus elevados custos; nesse contexto, verifica-se um alargamento dos escopos e dos mecanismos de controle da atividade administrativa, nas suas variadas modalidades, com destaque para o incremento da tutela judicial dessa atividade e pela efetivação do controle social.

2. Na busca de respostas e soluções para essa insatisfação com a atividade estatal, foram propostos novos parâmetros para a gestão pública, com uma crescente tendência a buscar, na atividade privada, os elementos necessários para a sua transformação. $\mathrm{O}$ sistema jurídico-administrativo, então, como reflexo da influência de modos gestionários das empresas privadas que se pretende sejam aplicados ao setor público, igualmente passa a receber institutos jurídicos do Direito Privado ou tem remodelada a dimensão ou significação dos seus próprios institutos. A partir dos anos 1990, após uma análise dos problemas estruturais da Administração Pública brasileira, uma reforma foi introduzida no ordenamento constitucional, com a previsão de novos conceitos, institutos, mecanismos de caráter eminentemente gerencial. Dentre as modificações, foi feita a inclusão da eficiência entre os expressos princípios constitucionais aplicados à atividade administrativa.

3. A inclusão do Princípio da Eficiência no sistema jurídico e sua formulação expressa no art. 37 da Constituição Federal, ao lado da legalidade, impessoalidade, moralidade e publicidade, tem, como uma de suas consequências práticas e imediatas, a possibilidade de um controle objetivo da atividade administrativa sob a perspectiva da eficiência. Esse controle, contudo, possui especificidades relacionadas não só aos órgãos legitimados para a sua realização, mas, sobretudo, aos meios e aos limites dessa atividade controladora.

4. O ordenamento constitucional brasileiro possui um complexo sistema de controle com diversos objetivos e alcances; a partir desse sistema, pode-se identificar claramente uma autonomia da atividade controladora, referida expressamente na atual redação da Lei de Introdução às Normas do Direito Brasileiro. Esse controle é realizado 
pela própria Administração (sentido estrito), por órgãos externos ou diretamente pela sociedade.

5. Um dos órgãos que desempenham a atividade de controle externo é o Tribunal de Contas; independente e essencial à República, possui competências constitucionais e legais próprias, privativas e essenciais ao exercício do controle externo. No atual ordenamento constitucional, o Tribunal de Contas assumiu a condição de principal órgão de controle dos atos administrativos que direta ou indiretamente tenham relação com a execução orçamentária ou impacto sobre o patrimônio público, devendo exercer o controle não só dos aspectos relacionados à verificação da regularidade da despesa, mas também da legitimidade e da própria qualidade da despesa pública.

6. De acordo com a Constituição brasileira em vigor, o Tribunal de Contas deve exercer uma fiscalização contábil, financeira, orçamentária, operacional e patrimonial da Administração Pública, adotando enfoques quanto à legalidade, legitimidade e economicidade da despesa, dentre outros aspectos. Os controles de legitimidade e de economicidade, inegavelmente envolvem, de alguma forma, um controle de mérito, não significando, contudo, limitação à discricionariedade administrativa.

7. Não resta dúvida que, assim, a eficiência administrativa se inclui entre as possibilidades e obrigações de controle do Tribunal de Contas, já que tanto a eficácia da ação administrativa como a eficiência no seu sentido estrito estão inseridas nas ideias de legitimidade e economicidade, traduzidas em aspectos relacionados, por exemplo, com a produtividade, celeridade e qualidade da atuação dos agentes públicos e do próprio funcionamento da estrutura administrativa e do seu modo de organização. Neste contexto, pode-se afirmar que o princípio da eficiência assume a condição de instrumento de uma Administração Pública orientada para resultados.

8. Forçoso é ver que o controle da eficiência possui características bem diferentes do que qualquer outro tipo de perspectiva de controle e que não existe uma metodologia única de controle de eficiência, nem se pode dizer que haja um momento específico para esse controle ou mesmo que suas consequências sejam predeterminadas.

9. Embora muito se refira ao Poder Judiciário no que diz respeito ao controle da eficiência, em decorrência da inafastabilidade da tutela jurisdicional, concluímos que os tribunais de contas são órgãos de controle técnico da atividade administrativa, previstos constitucionalmente para essa especializada atividade de controle e que o controle da 
eficiência administrativa é fundamentalmente uma atividade desses órgãos; não que o Poder Judiciário não possa examinar atos administrativos sob o ponto de vista da eficiência, mas essa análise possui limitações decorrentes da falta de especialização dos órgãos judiciais.

10. A fiscalização exercida pelos tribunais de contas decorre de uma obrigação constitucional que não depende da provocação de ninguém. É sistemático e contínuo; significa que, quanto à eficiência, as fiscalizações e auditorias dos tribunais de contas devem necessariamente examinar os atos administrativos também sob o aspecto da economicidade (art. 70, caput, da CF/1988) e, em última análise, sob o aspecto da eficiência, no seu sentido amplo. Essa perspectiva permite uma análise global da eficiência administrativa, indo desde a verificação de resultados produzidos por uma determinada política pública, por exemplo, até a análise do desempenho de um ente público durante um certo período, com abordagens que podem ser relacionadas à receita e à despesa públicas. Permite, igualmente, comparações de desempenho entre entes públicos ou atividades públicas, ou mesmo análises comparativas por períodos.

11. Nesse contexto, a avaliação dos resultados da atividade da Administração deve ser o enfoque principal do controle. O ordenamento constitucional brasileiro não só admite como exige que o controle se volte para a avaliação de resultados da ação administrativa com o objetivo de analisar, entre tantos outros aspectos, a eficiência dos gestores; as auditorias operacionais se constituem no principal instrumento de fiscalização e avaliação de eficiência, efetividade e eficácia da ação administrativa.

12. Ressaltamos a experiência estrangeira com as auditorias de performance ou de resultados em países europeus, como o Reino Unido, a França, a Holanda, a Suécia, a Finlândia e Portugal, além dos Estados Unidos e o Canadá. No Brasil, demonstramos que o Tribunal de Contas da União e os Tribunais dos Estados as têm utilizado largamente sob a denominação de auditorias operacionais. Mas não se pode negar as possibilidades de verificação da atividade administrativa e de seus resultados através, também, das auditorias de regularidade, notadamente quanto ao aspecto da economicidade (eficiência econômica). Como consequência, visualizamos a possibilidade de que o controle da eficiência realizado pelos tribunais de contas possa resultar em decisões que cominem sanções aos gestores, quer pela verificação de um aspecto dela (economicidade), quer pela dimensão ampla da eficiência, nas hipóteses de serem verificadas ações ou omissões administrativas que provoquem uma ineficiência estrutural da administração. 
13. Utilizando-se de auditorias operacionais ou de regularidade, os tribunais de contas possuem amplas possibilidades de controle da eficiência administrativa, quer analisando políticas públicas, quer examinando a execução dos serviços públicos, quer, ainda, perquirindo as alocações de receitas nos orçamentos públicos, dentre tantas outras possibilidades.

14. Estando as políticas públicas diretamente associadas à programação da atividade administrativa e às definições relacionadas ao orçamento, por meio deles podem ser examinados aspectos relacionados às prioridades eleitas e à qualidade do gasto público, na medida em que a fiscalização orçamentária examina, dentre tantos outros aspectos, se as leis orçamentárias estão cumprindo adequadamente o seu objetivo de programação e em que nível isso se dá.

15. Outra possibilidade é a avaliação específica da eficiência dos serviços prestados pela Administração Pública, voltando-se para a verificação de sua qualidade, o que compreende o exame das soluções dadas pela Administração para a execução do serviço, prestado diretamente ou delegado a um particular. O controle da eficiente prestação do serviço pode ser objeto de investigação dos tribunais de contas, por meio da verificação objetiva das condições pelas quais ele é prestado, pela observância das obrigações legalmente fixadas para a prestação do serviço público e pelo nível de satisfação do usuário.

16. Por fim, enfrentamos a questão relacionada aos parâmetros objetivos para a análise da eficiência, o que resultou na observação da importância do planejamento estratégico do órgão ou entidade como um instrumento de verificação e comparação dos resultados da atividade administrativa em relação às metas inicialmente fixadas, além de outros indicadores, como as experiências anteriores da Administração, as observações de relatórios de auditoria dos órgãos de controle, os alertas expedidos em decorrência da legislação de responsabilidade fiscal e as respostas às consultas formuladas aos tribunais de contas.

17. Acreditando termos, por meio deste trabalho, contribuído de alguma forma para a discussão doutrinária sobre o papel destinado ao Tribunal de Contas, no controle da eficiência administrativa, ainda que verificando que há aspectos não examinados com a atenção merecida - e, portanto, longe de imaginar que o estudo se encontra encerrado - concluímos, afirmando: 
a) O Princípio da Eficiência previsto no art. 37 da Constituição Federal impõe um controle objetivo da Administração Pública sob a perspectiva dos resultados de sua atuação, possuindo especificidades relacionadas aos órgãos legitimados para a sua realização, aos meios e aos limites dessa atividade controladora;

b) O controle da eficiência administrativa deve ser sistemático e contínuo, sendo o Tribunal de Contas o órgão constitucionalmente destinado, de forma precípua, ao exercício dessa atividade controladora, possuindo as condições jurídicas e técnicas para isso;

c) Podem os tribunais de contas, a partir de auditorias de resultados ou de regularidade, emitir relatórios expedindo recomendações visando à melhoria das atividades administrativas, ou mesmo decisões que façam determinações, apliquem sanções ou, ainda, rejeitem as contas de agentes públicos ineficientes. 


\section{REFERÊNCIAS}

AGUIAR, Afonso Gomes; AGUIAR, Márcio Paiva. O Tribunal de Contas na ordem constitucional. São Paulo: ABC Editora, 2003.

AGUIAR, Ubiratan Diniz de; ALBUQUERQUE, Márcio André Santos de; MEDEIROS, Paulo Henrique Ramos. A administração pública sob a perspectiva do controle externo. 1. ed. 1. reimpr. Belo Horizonte: Ed. Fórum, 2011.

ALBUQUERQUE, Frederico de Freitas Tenório de. A auditoria operacional e seus desafios: um estudo a partir da experiência do Tribunal de Contas da União. Rio de Janeiro: Renovar, 2007.

ALEXY, Robert. Teoria dos direitos fundamentais. Tradução de Virgílio Afonso da Silva. 2. ed. São Paulo: Malheiros, 2017.

ALMEIDA, Fernando Menezes. A noção constitucional de "administração pública" aplicada ao Poder Judiciário. In: CONTI, José Maurício (Org.). Poder Judiciário: orçamento, gestão e políticas públicas. São Paulo: Almedina Brasil, 2017. v. 1, p. 17-28.

ALMEIDA, Rafael Alves de. Governança colaborativa em políticas públicas. Rio de Janeiro: Tamanduá, 2015.

ALVES, Francisco Sérgio Maia. Controle da Administração Pública pelo Tribunal de Contas da União: espaço objetivo de incidência e parâmetro de legalidade. Interesse Público - IP, Belo Horizonte, v. 20, n. 108, mar./abr. 2018.

AMARAL, Diogo Freitas do. Curso de direito administrativo. 2. ed. Coimbra: Ed. Almedina, 2014. v. 2.

AMARAL, Diogo Freitas do. Curso de direito administrativo. 3. ed. Coimbra: Ed. Almedina, 2006. v. 1.

ANTUNES, Luís Filipe Colaço. A ciência jurídica administrativa. Coimbra: Ed. Almedina, 2014.

ARAGÃO, Alexandre Santos de. Interpretação consequencialista e análise econômica do direito público à luz dos princípios constitucionais da eficiência e da economicidade. Interesse Público - IP, Belo Horizonte, ano 11, n. 57, p. 11-30, set./out. 2009.

ARAÚJO, Edmir Netto de. Curso de direito administrativo. 8. ed. São Paulo: Saraiva, 2018.

BACELLAR FILHO, Romeu Felipe (Coord) e outros. Direito administrativo contemporâneo: estudos em memoria ao Professor Manoel de Oliveira Franco Sobrinho. 2. ed. rev. e ampl. Belo Horizonte: Fórum, 2011. 
BAHENA, Kele Cristiani Diogo. O princípio da moralidade administrativa e seu controle pela lei de improbidade. Curitiba: Juruá, 2004.

BANDEIRA DE MELLO, Celso Antônio. Curso de direito administrativo. 30. ed. rev. e atual. São Paulo: Malheiros, 2013.

BANDEIRA DE MELLO, Celso Antônio. Funções dos Tribunais de Contas. Revista de Direito Público, São Paulo, n. 72, out./dez. 1984.

BAPTISTA, Patrícia. Transformações do direito administrativo. Rio de Janeiro: Renovar, 2003.

BAQUER, Lorenzo Martin-Retortillo. Del derecho administrativo de nuestro tempo. Buenos Aires: Ediciones Ciudad Argentina, 1996.

BARROSO, Luís Roberto. Constitucionalidade e legitimidade da criação do Conselho Nacional de Justiça. Interesse Público - IP, Belo Horizonte, v. 6, n. 30, p. 13-38, mar./abr. 2005.

BATISTA JÚNIOR, Onofre Alves. Princípio constitucional da eficiência administrativa. 2. ed. rev. e atual. Belo Horizonte: Fórum, 2012.

BAUDU, Aurélien. Droit des finances publiques. Paris: Dalloz, 2015.

BENTO, Leonardo Valles. Governança e governabilidade na reforma do Estado: entre eficiência e democratização. Barueri: Manole, 2003.

BITTENCOURT, Marcus Vinicius Corrêa. Controle das concessões de serviço público. Belo Horizonte: Ed. Fórum, 2006.

BOZEMAN, Barry (Coord.). La gestión pública: su situación actual. México: Colegio Nacional de Ciencias Políticas y Administracion Pública, A.C; Universidad Autónoma de Tlaxcala; Fondo de Cultura Económica, 1998.

BRESSER PEREIRA, Luiz Carlos. Da administração pública burocrática à gerencial. Revista do Serviço Público, Brasília, ano 47, v. 120, n. 1, p. 7-40, jan./abr. 1996.

BRESSER PEREIRA, Luiz Carlos. Reforma do Estado para a cidadania: a reforma gerencial brasileira na perspectiva internacional. São Paulo: Editora 34, 2002.

BRITTO, Carlos Ayres. O Regime Constitucional dos Tribunais de Contas. Revista Diálogo Jurídico, Salvador, v. 1, n. 9, dez. 2001. Disponível em: http://direitopublico.com.br/pdf_9/DIALOGO-JURIDICO-09-DEZEMBRO-2001CARLOS-AYRES-BRITTO. Acesso em: 26 jun. 2017.

BUGARIN, Paulo Soares. Princípio constitucional da economicidade na jurisprudência do Tribunal de Contas da União. 2. ed. rev. e ampl. Belo Horizonte: Fórum, 2011.

CABRAL, Flávio Garcia. O conteúdo jurídico da eficiência administrativa. Belo Horizonte: Fórum, 2019. 
CAGGIANO, Álvaro Theodor Herman Salem. O controle judicial da eficiência administrativa. Tese (Doutorado) - Programa de Pós-graduação em Direito da Faculdade de Direito. Universidade de São Paulo. Orientador Edmir Netto de Araújo. São Paulo, 2017.

CAMPOS, Ricardo (Org.). Crítica da ponderação: método constitucional entre a dogmática jurídica e a teoria social. São Paulo: Saraiva, 2016.

CANOTILHO, J.J. Gomes. Direito constitucional. 6. ed. rev. Coimbra: Almedina, 1993.

CANOTILHO, J.J. Gomes. Direito constitucional e teoria da Constituição. 3 ed. Coimbra: Almedina, 1999.

CANOTILHO, J.J. Gomes; MOREIRA, Vital. Constituição da República Portuguesa anotada. 4. ed. Coimbra: Coimbra Editora, 2014. v. 2.

CARDÓN, Rubén C. A. Estudios sobre tribunales de cuentas y de control público. Salta: Comision Bicameral Examinadora de Autores Salteños, 1996.

CARVALHO FILHO, José dos Santos. Manual de direito administrativo. 9. ed. rev. ampl. e atual. Rio de Janeiro: Lumen Juris, 2002.

CARVALHO, André Castro. O impacto orçamentário da atuação do poder judiciário nas tutelas concessivas de medicamentos. In: AMARAL JÚNIOR, José Levi Mello do (Coord.). Estado de direito e ativismo judicial. São Paulo: Quartier Latin, 2010. p. 13-45.

CICERO, Nidia Karina. Servicios Publicos: Control y Proteccion. Buenos Aires: Facultad de Derecho y Ciencias Sociales - Universidade de Buenos Aires; Ediciones Ciudad Argentina, 1996.

CITADINI, Antonio Roque. O controle externo da administração pública. São Paulo: Ed. Max Limonad, 1995.

CONRADO, Márcio Macedo; MENEGUIN, Fernando B. Impactos da Lei n. 13.655/2018 nos órgãos de controle e seus reflexos na Administração Pública. Revista Brasileira de Direito Público - RBDP, Belo Horizonte, ano 17, n. 67, out./dez. 2019.

CORRALO, Giovani da Silva. Silêncio, eficiência e eficácia nas administrações municipais brasileiras. A\&C-Revista de Direito Administrativo \& Constitucional, Belo Horizonte, ano 19, n. 76, p. 253-269, abr./jun. 2019.

COSTA, Luiz Bernardo Dias. Tribunal de Contas: evolução e principais atribuições no Estado Democrático de Direito. Belo Horizonte: Fórum, 2006.

COSTALDELLO, Ângela Cássia. Aportes para um ideário brasileiro de gestão pública: a função do controle externo. In: SILVEIRA, Raquel Dias da; CASTRO, Rodrigo Pironti Aguirre de (Coords.). Estudos dirigidos de gestão pública na América Latina. Belo Horizonte: Fórum, 2011. v. 1, p. 33-51. 
COSTÓDIO FILHO, Ubirajara. A Emenda Constitucional n. 19/98 e o princípio constitucional da eficiência na administração pública. Revista do Tribunal de Contas do Estado do Paraná, Curitiba, n. 129, p. 66-78, jan./mar. 1999. Disponível em https://revista.tce.pr.gov.br/wp-content/uploads/2019/12/Revista-do-Tribunal-de-Contasdo-Paran\%C3\%A1-n.-129-de-Janeiro-Mar\%C3\%A7o-de-1999.pdf. Acesso em: 10 jul. 2020 .

CUNDA, Daniela Zago Gonçalves da. Controle de sustentabilidade pelos Tribunais de Contas: proposta de marco legal a ser utilizado no controle externo concretizador da sustentabilidade ambiental. Interesse público - IP, Belo Horizonte, ano 18, n. 96, p. 187218, mar./abr. 2016.

CHAPUS, René. Droit administratif general. 15. ed. Paris: Montchrestien, 2001. t. 1.

CHAVES, Francisco Eduardo Carrilho. Controle externo da gestão pública: a fiscalização pelo Legislativo e pelos Tribunais de Contas. 2. ed. rev. atual. Niterói: Impetus, 2009.

CHRÉTIEN, Patrice; CHIFFLOT, Nicolas; TOURBE, Maxime. Droit administratif. 14. ed. Paris: Dalloz, 2014.

DI PIETRO, Maria Sylvia Zanella. Direito administrativo. São Paulo: Atlas, 2015.

DÍAZ ROCA, Rafael. Teoría general del derecho. Madrid: Tecnos, 1997.

DOTTI, Marinês Restellato. Governança nas contratações públicas: aplicação efetiva de diretrizes, responsabilidade e transparência. Inter-relação com o direito fundamental à boa administração e o combate à corrupção. Belo Horizonte: Fórum, 2018.

DUPUIS, Georges; GUÉDON, Marie-José; CHRÉTIEN, Patrice. Droit administratif. 2. ed. Paris: Dalloz, 2011.

DWORKIN, Ronald. Los derechos en serio. Tradução de Marta Guastavino. Barcelona: Editorial Ariel, 2002.

FARIA, Edimur Ferreira de. Autocontrole da administração pública. In: FARIA, Edimur Ferreira de (Coord.). Controle da administração pública direta e indireta e das concessões. Belo Horizonte: Fórum, 2018.

FERNANDES, Jorge Ulisses Jacoby. Limites à revisibilidade judicicial das decisões dos Tribunais de Contas. Revista do Tribunal de Contas da União, Brasília, v. 27, n. 70, p. 39-72, out./dez. 1996.

FERNANDES, Jorge Ulisses Jacoby. Tribunais de Contas do Brasil: jurisdição e competência. Belo Horizonte: Ed. Fórum, 2003.

FERRAZ, Luciano. Controle e consensualidade. Belo Horizonte: Fórum, 2019. 
FERREIRA JÚNIOR, Adircélio de Moraes; CARDODO, Juliana Francisconi. A aferição qualitativa das contas de governo pelo Tribunais de Contas pelos Tribunais de Contas: necessidade de mudança do patamar de análise. Interesse Público - IP, Belo Horizonte, ano 15 , n. 82, p. 253-272, nov./dez. 2013.

FERREIRA JÚNIOR, Silvio. Desempenho fiscal e gestão pública nas esferas estaduais: uma avaliação das execuções orçamentárias no período de 1995 a 2004. In: Finanças Públicas: XI Prêmio Tesouro Nacional, 2006: coletânea de monografias. Ministério da Fazenda, Secretaria do Tesouro Nacional. Brasília: Editora Universidade de Brasília, 2007. p. 887-953.

FIGUEIREDO, Marcelo. O controle da moralidade na Constituição. São Paulo: Malheiros, 1999.

FLORES, Alfredo de J. O estudo de casos na perspectiva da metodologia jurídicofilosófica. Revista Eletrônica do Curso de Direito da UFSM, v. 4, n. 3, 2009. Disponível em: http://dx.doi.org/10.5902/198136947036. Acesso em: 12 jun. 2016.

FONSECA, Antonio. O princípio da eficiência: impacto no direito público e improbidade. In: SAMPAIO, José Adércio Leite; COSTA NETO, Nicolau Dino de Castro; SILVA FILHO, Nívio de Freitas; ANJOS FILHO, Robério Nunes dos (Coords.). Improbidade administrativa: 10 anos da Lei 8.429/92. Belo Horizonte: Livraria Del Rey Editora, 2002. p. 35-66.

FRANÇA, Phillip Gil. O controle da administração pública: tutela jurisdicional, regulação econômica e desenvolvimento. São Paulo: Editora Revista dos Tribunais, 2008.

FRANÇA, Vladimir da Rocha. Eficiência administrativa na Constituição Federal. Revista de Direito Administrativo, Rio de Janeiro, v. 220, p. 165-177, abr. 2000.

FRANCO, Antonio L. de Sousa. Finanças públicas e direito financeiro. 4. ed. 9. reimpr. Coimbra: Almedina, 2002. v. 1.

FREITAS, Juarez. Discricionariedade administrativa e o direito fundamental à boa administração pública. São Paulo: Malheiros Ed., 2007.

FREITAS, Juarez. Estudos de direito administrativo. 2. ed. São Paulo: Malheiros Ed., 1997.

FREITAS, Juarez. A interpretação sistemática do direito. 5. ed. São Paulo: Malheiros, 2010.

FREITAS, Juarez; CUNDA, Daniela Zago Gonçalves da; REIS, Fernando Simões dos. A atuação dos Tribunais de Contas em prol da indução das energias renováveis. Interesse público - IP, Belo Horizonte, ano 19, n. 102, p. 129-148, mar./abr. 2017.

FROTA, Hidemberg Alves da. O princípio tridimensional da proporcionalidade no direito administrativo: um estudo à luz da principiologia do direito constitucional e administrativo, bem como da jurisprudência brasileira e estrangeira. Rio de Janeiro: GZ Ed., 2009. 
FURTADO, J. R. Caldas. Direito financeiro. 4. ed. rev. ampl. e atual. Belo Horizonte: Fórum, 2013.

FURTADO, Lucas Rocha. Curso de direito administrativo. 5. ed. Belo Horizonte: Ed. Fórum, 2016.

GABARDO, Emerson. Princípio constitucional da eficiência administrativa. São Paulo: Dialética, 2002.

GABARDO, Emerson. Princípio da eficiência, O. In: NUNES Jr., Vidal Serrano; ZOCKUM, Maurício; ZOCKUM, Carolina Zancaner; FREIRE, André Luiz (Coord. t. 2). Enciclopédia jurídica da PUC-SP. Coordenação geral: Celso Fernandes Campilongo, Álvaro de Azevedo Gonzaga, André Luiz Freire. 1. ed. São Paulo: Pontifícia Universidade Católica de São Paulo, 2017. t. 2: Direito Administrativo e Constitucional. Disponível em: https://enciclopediajuridica.pucsp.br/verbete/82/edicao-1/principio-daeficiencia,-o. Acesso em: 10 jul. 2020.

GAMEIRO, António Ribeiro; COSTA, Nuno Moita da; PIMENTEL, Liliana Marques. As finanças públicas e o seu controlo. Coimbra: Almedina, 2020.

GARCÍA DE ENTERRÍA, Eduardo; FERNANDEZ, Tomás-Ramón. Curso de direito administrativo. São Paulo: Ed. Revistas dos Tribunais, 1990.

GASPARINI, Diogenes. Direito administrativo. 4. ed. São Paulo: Saraiva, 1995.

GIAMUNDO NETO, Giuseppe. As garantias do processo no Tribunal de Contas da União: princípios constitucionais, Código de Processo Civil/2015 e a Lei de Introdução às normas do Direito Brasileiro - LINDB. São Paulo: Thomson Reuters Revista dos Tribunais, 2019.

GONÇALVES, Pedro Costa. Ensaio sobre a boa governação da administração pública a partir do mote da "New Public Governance". In: GONÇALVES, Pedro Costa et al. $O$ governo da administração pública. Coimbra: Almedina, 2013. (Coleção Governança $\mathrm{Lab})$.

GONÇALVES, Pedro Costa. Manual de direito administrativo. Coimbra: Almedina, 2020. v. 1 .

GORDILLO, Agustín. Tratado de derecho administrativo. 5. Ed. Buenos Aires, 2000. t. 1.

GRACIE, Ellen. Notas sobre a revisão judicial das decisões do Tribunal de Contas da União pelo Supremo Tribunal Federal. Revista do Tribunal de Contas da União, ano 38, n. 110, p. 7-14, set./dez. 2007. Disponível em: https://revista.tcu.gov.br/ojs/index.php/RTCU/article/view/413/482.

GUERRA, Evandro Martins. Os controles externo e interno da administração pública e os tribunais de contas. Belo Horizonte: Ed. Fórum, 2003. 
GUIMARÃES, Edgar. Controle das licitações públicas. São Paulo: Dialética, 2002.

HARADA, Kiyoshi. Direito financeiro e tributário. 22. ed. São Paulo: Atlas, 2013.

HOMERCHER, Evandro T. O Tribunal de Contas e o controle da efetividade dos direitos fundamentais. Interesse Público - IP, Belo Horizonte, ano 7, n. 35, p. 315-343, jan./fev. 2006 .

THE INTERNATIONAL ORGANIZATION OF SUPREME AUDIT INSTITUTIONS. INTOSAI. ISSAI 100 - Fundamental Principles of Public-sector Auditing, Disponível em:

https://www.intosai.org/fileadmin/downloads/documents/open_access/ISSAI_100_to_40 0/issai_100/issai_100_en.pdf.

JANNER, Rémy. Avaliação de resultado da função pública no controle externo francês e o papel das Câmaras Regionais de Contas. Trad. Márcia Farias. Revista do Tribunal de Contas do Distrito Federal, Brasília, n. 34, p. 9-36, jan./dez. 2008.

JUSTEN FILHO, Marçal. Comentários à lei de licitações e contratos administrativos. 15. ed. São Paulo: Dialética, 2012.

JUSTEN FILHO, Marçal. Curso de direito administrativo. 7. ed. rev. e atual. Belo Horizonte: Ed. Fórum, 2011.

KELLES, Márcio Ferreira. Controle da administração pública democrática: Tribunal de Contas no controle da LRF. Belo Horizonte: Ed. Fórum, 2007.

LEME, Rogerio. Gestão por competências no setor público. Rio de Janeiro: Qualitymark, 2011.

LIMA, Rafael Bellem de. Regras na teoria dos princípios. São Paulo: Malheiros, 2014.

LIMA, Ruy Cirne. Princípios de direito administrativo. 7. ed. São Paulo: Malheiros Ed., 2007.

LIMBERGER, Têmis. Atos da administração lesivos ao patrimônio público. Porto Alegre: Livraria do Advogado Ed., 1998.

LOMBARD, Martine. L'avenir du service public au service du public. In: CHEVALIER, Jean-Marie; EKELAND, Ivar; FRISON-ROCHE, Marie-Anne (Eds.). L'idée de service public est-elle encore soutenable? Paris: Presses Universitaires de France, 1999. p. 247252.

MANCUSO, Rodolfo de Camargo. A ação civil pública como instrumento de controle judicial das chamadas políticas públicas. In: MILARÉ, Édis (Coord.). Ação civil pública: Lei 7.347/1985 - 15 anos. 2. ed. São Paulo: Editora Revista dos Tribunais, 2002. p. 753-798.

MARQUES NETO, Floriano de Azevedo. Os grandes desafios do controle da Administração Pública. Fórum de Contratação e Gestão Pública - FCGP, Belo Horizonte, ano 9, n. 100, p. 7-30, 2010. 
MARRARA, Thiago. Controle interno da administração pública: suas facetas e seus inimigos. In: MOTTA Fabrício; GABARDO, Emerson (Coords.). Limites do controle da administração pública no Estado de direito. Curitiba: Íthala, 2019. p. 251-266.

MARRARA, Thiago. Direito administrativo brasileiro: transformações e tendências. In: MARRARA, Thiago (Coord.). Direito administrativo: transformações e tendências. São Paulo: Almedina. 2014. p. 17-46.

MARTINS, Maria d'Oliveira. A despesa pública justa: uma análise jurídicoconstitucional do tema da justiça na despesa pública. Coimbra: Almedina, 2016.

MARTINS JÚNIOR, Wallace Paiva. A processualização do direito administrativo. In: In: MARRARA, Thiago (Coord.). Direito administrativo: transformações e tendências. São Paulo: Almedina. 2014. p. 287-326.

MEDAUAR, Odete. Controle da administração pública. 2. ed. rev. atual. ampl. São Paulo: Editora Revista dos Tribunais, 2012.

MEDAUAR, Odete. Direito administrativo moderno. São Paulo: Ed. Revista dos Tribunais, 2012.

MEIRELLES, Hely Lopes. Direito administrativo brasileiro. 12. ed. atual. São Paulo: Editora Revista dos Tribunais, 1986.

MEIRELLES, Hely Lopes. Direito administrativo brasileiro. 35. ed. São Paulo: Malheiros Ed., 2009.

MELLO, Oswaldo Aranha Bandeira de. Princípios gerais do direito administrativo. 3. ed. São Paulo: Malheiros Ed., 2007. v. 1.

MENDES, Gilmar; COELHO, Inocêncio Mártires; BRANCO, Paulo Gustavo Gonet. Curso de direito constitucional. 2. ed. rev. e atual. São Paulo: Saraiva, 2008.

MENDES, Marcos (org.). Gasto público eficiente: propostas para o desenvolvimento do Brasil. São Paulo: Topbooks Ed., 2006.

MILESKI, Hélio Saul. O controle da gestão pública. 3. ed. rev. atual. e aum. Belo Horizonte: Fórum, 2018.

MILESKI, Hélio Saul. O controle público exercido sobre a atividade financeira e orçamentária do Estado: dados comparativos entre os sistemas de controles exercidos no âmbito da União Europeia e do Brasil. Interesse Público - IP, Belo Horizonte, ano 11, n. 53, p. 29-68, jan./fev. 2009.

MIRAGEM, Bruno. A nova administração pública e o direito administrativo. 2. ed. São Paulo: Editora Revista dos Tribunais, 2013.

MIRANDA, Jorge. Manual de direito constitucional. 3. ed. Coimbra: Coimbra Editora, 1996. t. 2. 
MODESTO, Paulo. Notas para um debate sobre o princípio da eficiência. Revista Interesse Público, Belo Horizonte, ano 2, no. 7, p. 65-75, jul./set. 2000.

MODESTO, Paulo. É possível superar o clientelismo no Brasil? Argumentos jurídicos e sugestões para limitar a criação e o provimento abusivo de cargos públicos em comissão nos 30 anos da Constituição de 1988. In: DI PIETRO Maria Sylvia Zanella; MOTTA Fabrício (Coords.). O direito administrativo nos 30 anos da Constituição. Belo Horizonte: Fórum, 2018. p. 283-316.

MORAES, Alexandre de. Direito constitucional administrativo. 2. ed. atual. São Paulo: Atlas, 2005.

MOREIRA NETO, Diogo de Figueiredo. Controle de contas e o equilíbrio entre poderes: notas sobre a autonomia do sistema de controle externo. Interesse Público, Belo Horizonte, v. 19, n. 101, jan./fev. 2017. 2018

MOREIRA NETO, Diogo de Figueiredo. Curso de direito administrativo: parte introdutória, parte geral e parte especial. 15. ed. Rio de Janeiro: Forense, 2009.

MOREIRA NETO, Diogo de Figueiredo. Mutações do direito público. Rio de Janeiro: Ed. Renovar, 2006.

MOREIRA NETO, Diogo de Figueiredo. Quatro paradigmas do direito administrativo pós-moderno: legitimidade, finalidade, eficiência, resultados. Belo Horizonte: Ed. Fórum, 2008.

MOTTA, Fabrício; GODINHO, Heloísa Helena Antonacio M. Administração pública e Judiciário: eficiência do gasto público e modernização da gestão. In: CONTI, José Maurício (Org.). Poder Judiciário: orçamento, gestão e políticas públicas. São Paulo: Almedina Brasil, 2017. v. 1, p. 177-195.

NARDES, João Augusto Ribeiro; ALTOUNIAN, Cláudio Sarian; VIEIRA, Luis Afonso Gomes. Governança pública: o desafio do Brasil. Belo Horizonte: Ed. Fórum, 2014.

NOHARA, Irene Patrícia. Constituição Federal de 1988: comentários ao capítulo da Administração Pública: cap. VII do título III: da organização do Estado: artigos 37 a 43. São Paulo: Editora Atlas, 2015. (Coleção Direito Administrativo Positivo).

NOHARA, Irene Patrícia. Reforma administrativa e burocracia: impacto da eficiência na configuração do direito administrativo brasileiro. São Paulo: Atlas, 2012.

OLIVEIRA, Odilon Cavallari de. Alterações à Lei de Introdução às Normas do Direito brasileiro. In: PINTO, Élida Graziane; SARLET, Ingo Wolfgang; PEREIRA JÚNIOR, Jessé Torres; OLIVEIRA, Odilon Cavallari de. Política pública e controle: um diálogo interdisciplinar da Lei 13.655/2018, que alterou a Lei de Introdução às Normas do Direito brasileiro. Belo Horizonte: Fórum, 2018. 
OLIVEIRA, Rafael Carvalho Rezende. Princípios do direito administrativo. 2. ed. rev. atual. e ampl. Rio de Janeiro: Método, 2013.

ORGANIZATION FOR ECONOMIC COOPERATION AND DEVELOPMENT OECD. Policy brief. OECD Guidelines for managing conflict of interest in the public service. Paris: OCDE, 2005.

PAZZAGLINI FILHO, Marino. Princípios constitucionais reguladores da administração pública. São Paulo: Ed. Atlas, 2000.

PEDRA, Anderson Sant'Ana. Por uma "separação de poderes" à brasileira: Constituição de 1988 e a teoria tripartite de Montesquieu - Uma conta que não fecha. Interesse Público - IP, Belo Horizonte, v. 15, n. 78, mar./abr. 2013.

PEDREIRA, Ana Maria. Responsabilidade do estão por omissão: prevenção, precaução e controle como meios de evitar a ocorrência do dano. Dissertação (Mestrado) - Programa de Pós-Graduação em Direito da Faculdade de Direito da Universidade de São Paulo, São Paulo, 2013.

PEREIRA, Cláudia Fernanda de Oliveira Pereira (Org.). O novo direito administrativo brasileiro: o Estado, as agências e o terceiro setor. Belo Horizonte: Ed. Fórum, 2003.

PEREIRA JUNIOR, Jessé Torres. Controle judicial da administração pública: da legalidade estrita à lógica do razoável. Belo Horizonte: Ed. Fórum, 2005.

PEREZ, Marcos Augusto. A administração pública democrática: institutos de participação popular na administração pública. Belo Horizonte: Ed. Fórum, 2004.

PESTANA, Márcio. Direito administrativo brasileiro. Rio de Janeiro: Elsevier, 2008.

PINTO, Élida Graziane. Ciclo das políticas públicas e legitimidade compartilhada das escolhas alocativas: um estudo em busca da vinculação à força normativa do planejamento. In: PINTO, Élida Graziane et al. Politica pública e controle: um diálogo interdisciplinar da Lei 13.655/2018, que alterou a Lei de Introdução às Normas do Direito Brasileiro. Belo Horizonte: Fórum, 2018.

POLLITT, Christopher; SUMMA, Hilkka. Auditoria operacional e reforma da administração pública. In: POLLIT, Christopher; GIRRE, Xavier; LONSDALE, Jeremy; MUL, Robert; SUMMA, Hilkka; WAERNESS, Marit. Desempenho ou legalidade? Auditoria operacional e de gestão pública em cinco países. Trad. Pedro Buck. Belo Horizonte: Fórum, 2008.

PORTUGAL, André; KLEIN, Érico. A anti-teoria consequencialista como fundamento da nova LINDB. In: VALIATI, Thiago Priess, HUNGARO, Luís Alberto; CASTELLA, Gabriel Morettini (Coords.). A lei de introdução e o direito administrativo brasileiro. Rio de Janeiro: Lumen Juris, 2019.

PORTUGAL. Tribunal de Contas. Manual de auditoria: princípios fundamentais (MAPF), Lisboa, 2016. Disponível em: https://www.tcontas.pt/ptpt/NormasOrientacoes/ManuaisTC/Documents/mapf_20161107.pdf. 
RANIERI, Nina. Teoria do Estado: do Estado de Direito ao Estado Democrático de Direito. 2. ed. Barueri-SP: Manole, 2019.

REIS, Fernando Simões dos. Novas perspectivas para o controle da discricionariedade administrativa pelo Tribunal de Contas da União em auditorias operacionais. Interesse Público - IP, Belo Horizonte, ano 17, n. 89, p. 239-275, jan./fev. 2015.

RINCÓN PACHÓN, Jairo E. Administración pública, gerencia pública, gestión pública y gerencia social: análisis epistemológico. 2. ed. Bogotá: Ibañez, 2014.

RIVERO, Jean. Curso de direito administrativo comparado. São Paulo: Editora Revista dos Tribunais, 1995.

RIVERO, Jean; WALINE, Jean. Droit administratif. 18. ed. Paris: Dalloz, 2000.

ROLO, Nuno Miguel Cunha. Manual de administração e governação pública. Lisboa: AAFDL Editora, 2019. v. 1.

ROSILHO, André. Tribunal de Contas da União: competências, jurisdição e instrumentos de controle. São Paulo: Quartier Latin, 2019.

SANTOS, Andreia Brasil (Org.) et al. Estudos de casos em administração pública. Manaus: Ed. Universidade Federal do Amazonas, 2014.

SANTOS, Márcia Walquiria Batista dos; QUEIROZ, João Eduardo Lopes. Direito administrativo. Rio de Janeiro: Elsevier Ed., 2009. t. 2.

SARTAL, Estevam Palazzi. Influência da Lei de Introdução ao Direito Brasileiro na formulação de políticas públicas e no seu controle. Revista de Direito Público da Economia-RDPE, Belo Horizonte, ano 17, n. 66, p. 59-74, abr./jun. 2019.

SCHIRATO, Vitor Rhein. As agências reguladoras independentes e alguns elementos da Teoria Geral do Estado. In: ARAGÃO, Alexandre Santos de; MARQUES NETO, Floriano de Azevedo (Coords.). Direito administrativo e seus novos paradigmas. Belo Horizonte: Fórum, 2012.

SILVA, José Afonso. Curso de direito constitucional positivo. 22. ed. rev. e atual. São Paulo: Malheiros, 2003.

SOUSA, António Francisco de. Constituição da República de Angola: anotada e comentada. Porto: Vida Económica, 2014.

SOUSA, António Francisco de. Direito administrativo europeu. Porto: Vida Económica, 2016.

SOUSA, Marcelo Rebelo de; MATOS, André Salgado de. Direito administrativo geral: introdução e princípios fundamentais. 3. ed. Alfragide: Ed. Dom Quixote, 2008. t. 1. 
SOUTO, Marcos Juruena Villela. Direito administrativo da economia. 3. ed. Rio de Janeiro: Lumen Juris, 2003.

SOUZA, Rodrigo Pagani de. Em busca de uma administração pública de resultados. In: PEREZ, Marcos Augusto; SOUZA, Rodrigo Pagani de. Controle da administração pública. Belo Horizonte: Fórum, 2017. p. 39-61.

SOUZA, Rodrigo Pagani de; ALENCAR, Letícia Lins. O dever de contextualização na interpretação e aplicação do direito público. In: VALIATI, Thiago Priess, HUNGARO, Luís Alberto; CASTELLA, Gabriel Morettini (Coords.). A lei de introdução e o direito administrativo brasileiro. Rio de Janeiro: Lumen Juris, 2019.

SPECK, Bruno Wilhelm. Inovação e rotina no Tribunal de Contas da União: o papel da instituição superior de controle financeiro no sistema político-administrativo do Brasil. São Paulo: Fundação Konrad Adenauer, 2000.

STIRN, Bernard. Droit administratif: les sources constitutionnelles du droit administratif. 2. ed. Paris: L.G.D.J., 1995.

STOBER, Rolf. Direito administrativo econômico geral. São Paulo: Saraiva, 2012.

SUNDFELD, Carlos Ari (Coord.). Direito administrativo econômico. 1. ed. São Paulo: Malheiros Ed., 2000.

SUNDFELD, Carlos Ari; CÂMARA, Jachinto Arruda. O Tribunal de Contas da União e a regulação. In: FIGUEIREDO, Marcelo (Coord.) Novos rumos para o direito público: reflexões em homenagem à Professora Lúcia Valle Figueiredo. Belo Horizonte: Fórum, 2012. p. 59-68.

TAVARES, José F.F. Estudos de administração e finanças públicas. 2. ed. Coimbra: Ed. Almedina, 2014.

TERRINHA, Luís Heleno. O direito administrativo na sociedade: função, prestação reflexão do sistema jurídico-administrativo. Porto: Universidade Católica Editora Porto, 2017.

TOLLINI, Hélio Martins. Repensando a gestão das finanças públicas no Brasil. In: SALTO, Felipe; ALMEIDA, Mansueto (Orgs.) Finanças públicas: da contabilidade criativa ao resgate da credibilidade. Rio de Janeiro: Record, 2016.

TORRES, Ricardo Lobo. O Tribunal de Contas e o controle da legalidade, economicidade e legitimidade. Revista de Informação Legislativa - RIL, Brasília, v. 31, n. 121, p. 265-271, jan./mar. 1994.

TRIBUNAL DE CONTAS DA UNIÃO - TCU. Glossário de termos de Controle Externo. Disponível em: portal.tcu.gov.br.

UNGARO, Gustavo Gonçalves. Responsabilidade do Estado e direitos humanos. São Paulo: Saraiva, 2012. 
VALLE, Vanice Regina Lírio do. Direito fundamental à boa administração $e$ governança. Belo Horizonte: Fórum, 2011.

VALLE, Vanice Regina Lírio do. Direito fundamental à boa administração, políticas públicas eficientes e a prevenção do desgoverno. Interesse Público - IP, Belo Horizonte, ano 10, n. 48, p. 87-109, mar./abr. 2008.

VELLEY, Serge. Droit administratif. 8. ed. Paris: Vuibert, 2011.

YOUNES MORENO, Diego. Curso de derecho administrativo. 9. ed. Bogotá: Ed. Temis, 2014.

ZIMMER JUNIOR, Aloísio. Curso de direito administrativo. 2. ed. Porto Alegre: Verbo Jurídico, 2008.

ZYMLER, Benjamin. Direito administrativo e controle. 2. ed. Belo Horizonte: Ed. Fórum, 2009.

ZYMLER, Benjamin; ALMEIDA, Guilherme Henrique de La Rocque. O controle externo das concessões de serviços públicos e das parcerias público-privadas. Belo Horizonte: Ed. Fórum, 2005.

\section{Legislação e Jurisprudência}

BRASIL. Constituição da República Federativa do Brasil de 1967. http://www.planalto.gov.br/ccivil_03/Constituicao/Constituicao67.htm. Acesso em: 01 jun. 2020.

BRASIL. Constituição dos Estados Unidos do Brasil (de 18 de setembro de 1946). http://www.planalto.gov.br/ccivil_03/Constituicao/Constituicao46.htm. Acesso em: 01 jun. 2020.

BRASIL. Constituição dos Estados Unidos do Brasil, de 10 de novembro de 1937. Disponível em: http://www.planalto.gov.br/ccivil_03/Constituicao/Constituicao37.htm. Acesso em: 01 jun. 2020.

BRASIL. Decreto $n^{o}$ 9.991, de 28 de agosto de 2019. Disponível em: http://www.planalto.gov.br/ccivil_03/_Ato2019-2022/2019/Decreto/D9991.htm\#art35.

CONSELHO NACIONAL DE JUSTIÇA - CNJ. Resolução $n^{o} 111$ de 06/04/2010. Institui o Centro de Formação e Aperfeiçoamento de Servidores do Poder Judiciário CEAJud e dá outras providências. Disponível em https://atos.cnj.jus.br/atos/detalhar/130.

SUPERIOR TRIBUNAL DE JUSTIÇA - STJ. Jurisprudência do STJ. Disponível em: https://scon.stj.jus.br/SCON/jurisprudencia/toc.jsp. 
SUPREMO TRIBUNAL FEDERAL - STF. Mandado de Segurança 33.340 - Distrito Federal. Rel. Min. Luiz Fux. Data: 26/05/2015. Disponível em: http://redir.stf.jus.br/paginadorpub/paginador.jsp?docTP=TP\&docID=8978494. Acesso em: 23 jun. 2020.

SUPREMO TRIBUNAL FEDERAL - STF. Segundo Ag. Reg. em Mandado de Segurança 31.677 Distrito Federal. Rel. Min. Luiz Fux. Data: 04/05/2020. Disponível em: http://redir.stf.jus.br/paginadorpub/paginador.jsp?docTP=TP\&docID=752722610. Acesso em: 23 jul. 2020.

TRIBUNAL DE CONTAS DA UNIÃO - TCU. TC 003.673/2017-0 (apenso TC 000.524/2017-4). Disponível em: https://pesquisa.apps.tcu.gov.br/\#/documento/acordaocompleto/*/NUMACORDAO\%253 A2643\%2520ANOACORDAO $\% 253$ A2017/DTRELEVANCIA $\% 2520 \mathrm{desc} \% 252 \mathrm{C} \% 252$ 0NUMACORDAOINT\%2520desc/0/\%2520?uuid=9270dc80-dcdb-11ea-8633b1f79fa43788. 